\title{
FUSARIUM SOLANI INFECTION OF RED SWAMP CRAYFISH (PROCAMBARUS CLARKII)
}

\author{
MAHMOUD MOSTAFA MAHMOUD \\ Aquatic Animals Medicine and Management, Faculty of Veterinary Medicine, Assiut University, Assiut 71526, Egypt.
}

Received: 31 March 2019; Accepted: 7 April 2019

\begin{abstract}
In river Nile and its branches, numerous individuals of red swamp crayfish, Procambarus clarkii, displayed melanised areas in gills. To clarify the cause of these lesions, several isolates of Fusarium spp. were recovered. The fungi were first identified morphologically on culture media. Subsequently, molecular identification was carried out based on the internal transcribed spacer (ITS) region and beta-tubulin gene (TUB2) sequences. Based on GenBank database searches, the causative agent was identified as Fusarium solani. To fulfill Koch`s postulates, an experimental infection was induced using a representative isolate (ESHA-1). The challenged crayfish showed similar lesions noticed on naturally-infected ones, and the pathogen was re-isolated from the lesions of the infected individuals. Zinc oxide nanoparticles (ZnO NPs) exhibited a significant reduction in fungal growth. To our knowledge, this is the first record of Fusarium solani infection in red swamp crayfish inhabiting the River Nile.
\end{abstract}

Key words: Fusarium solani, Procambarus clarkii, ITS, TUB2, challenge, ZnO NPs

\section{INTRODUCTION}

In their habitat, either wild or cultured, red swamp crayfish are exposed to many pathogens including bacterial, fungal, viral and parasites as well (Abdallah et al., 2018; Baumgartner et al., 2009; Holdich et al., 2009; Yosra et al., 2016). One of the fungi known to infect various crustacean species including freshwater crayfish, lobster and shrimp, is genus Fusarium that induces melanisation and cuticle erosions (Alderman and Polglase, 1985; Chinain and Vey, 1988; Dörr et al., 2012; Hose et al., 1984; Khoa et al., 2004; Makkonen et al., 2013). Other potential chitinoclastic organisms have also been suggested as proposed disease agents (Edgerton et al., 2002). Fusarium sp. was also found as a saprophyte on white-clawed crayfish, Austropotamobius pallipes (Quaglio et al., 2006) without any obvious dangerous effects on the host. Epidemics may be more severe if several fungi or other pathogens act concomitantly (Dörr et al., 2012).

In an earlier investigation, Fusarium oxysporum was reported for the first time to cause a serious disease problem in cultured red sea bream, Pagrus major

Corresponding author: Dr. Mahmoud Mostafa Mahmoud E-mail address: mahmoud88@aun.edu.eg

Present address: Aquatic Animals Medicine and Management, Faculty of Veterinary Medicine, Assiut University, Assiut 71526, Egypt.
(Hatai et al., 1986), subsequently, some other studies have been conducted describing the diseases caused by different Fusarium spp. in crustacean hosts. Later on, Eroded swimmeret syndrome (ESS) affecting wild female signal crayfish, Pacifastacus leniusculus was found to be caused by multiple infections, one of which is Fusarium sp. resulting in swimmeret erosion. That syndrome induced population decline via reduced fecundity of crayfish with decreased juvenile recruitment as a result (Edsman et al., 2015). Another species of the genus Fusarium, $F$. avenaceum, targets the chitinised tissues, either hard or soft, of noble crayfish, Astacus astacus, and produces massive tissue erosion and burn spot disease (Makkonen et al., 2013).

Regarding Fusarium solani, at least 60 phylogenetically different species have been recorded (O'Donnell et al., 2012; O'Donnell et al., 2008). Many investigators have reported that Fusarium solani was found to be responsible for disastrous epizootics in cultured freshwater and saltwater crustaceans. Also, the infections have been reported in wild populations (Johnson, 1983). The pathogen mainly affects the gills and the cuticle. The lesions appear mainly on the dorsal abdomen, yet, they may extend to the whole abdomen giving a brown coloration (Chinain and Vey, 1988). Hence the name 'brown abdomen disease' was used. The manifestation of these brown patches is due to the melanisation process which is mediated by a complex enzyme activation sequence 
(prophenoloxidase activating system) (Soderhall and Smith, 1986). Fungal hyphae can invade the soft tissue and hard tissue of the exoskeleton as well.The fungus was isolated from lesions with black gills of cultured kuruma prawn, Penaeus japonicas (Khoa et $a l ., 2005)$. Infections due to $F$. solani was reported in other aquatic animals like the sea turtle, Caretta caretta (Sarmiento-Ramirez et al., 2010) as well as some fish species including sharks (Crow et al., 1995). In addition, more than 100 plant species belonging to 90 genera are affected by this fungus (Kolattukudy and Gamble, 1995). Also, the fungus has impacts on humans especially the immunocompromised individuals provoking high mortalities (Guarro, 2013; Nucci and Anaissie, 2007).

In this study, $F$. solani isolates were recovered and identified from red swamp crayfish as a possible candidate causing gill melanisation. Further identification of the pathogen by sequencing of both ITS region and beta-tubulin gene was carried out. The antifungal activity of zinc oxide nanoparticles was investigated and an inhibitory action on fungal growth was shown.

\section{MATERIALS AND METHODS}

\section{Crayfish sampling:}

Red swamp crayfish, Procambarus clarkii, were collected from the River Nile and its branches in Assiut city, and then transported to the wet lab in Fish diseases and Management Department at Assiut University. Sampled crayfish were 8 to $12 \mathrm{~cm}$ long. They were held in plastic tanks of 100 liters that had a water temperature of $25 \pm 1^{\circ} \mathrm{C}$ and $\mathrm{pH}$ of $8.0 \pm 0.2$ and the water was changed daily. Crayfish were fed once daily with commercial fine diet.

\section{Fungal isolation and identification:}

Putatively diseased crayfish with black coloration in the gills (Fig. 1) were subject to fungal isolation as was previously described (Abdallah et al., 2018). Briefly, crayfish were anesthetized by chilling on ice. Following disinfection of surface using 5\% sodium hypochlorite and $70 \%$ ethanol, small pieces of the melanised black gills were excised and inoculated onto both Sabouraud's dextrose agar (SDA) and potato dextrose agar (PDA) to which $250 \mu \mathrm{g} / \mathrm{mL}$ of chloramphenicol was added. Plates were incubated at $25^{\circ} \mathrm{C}$ until fungal hyphae appeared. For culture purification, a portion of the agar containing the growing mycelia was dissected and inoculated onto a new medium. In order to obtain a pure culture, a single spore culture was performed as was described previously by Jensen et al. (2013).

\section{Molecular characterization of the isolates:}

The isolated fungi were cultured on PDA and incubated at $25^{\circ} \mathrm{C}$ for 7 days. Fungal hyphae were collected from the agar plates using sterile distilled water and then followed by centrifugation at 16000 $\times \mathrm{g}$ for 5 minutes. Freeze dry homogenization was performed using liquid nitrogen in a sterile mortar until a fine powder was obtained. DNA extraction was carried out using the CTAB method described by Abdallah et al. (2018). The concentration and the purity of the obtained DNA were determined using Nanophotometer (Implen GmbH, Germany) measuring the optical density at $260 \mathrm{~nm}$ and ratio optical density at 260/280 $\mathrm{nm}$, respectively. DNA samples were stored at $-20^{\circ} \mathrm{C}$ until used.

Polymerase chain reactions (PCR) were conducted to amplify the fungal internal transcribed spacer (ITS) region using the primer set: ITS1F; CTTGGTCATTTAGAGGAAGTA and ITS4R; TCCTCCGCTTATTGATATGC (White et al., 1990) following the protocol of Romanelli et al. (2010). Amplification of the housekeeping gene; beta-tubulin (TUB2) was performed using the primer pair: T1/T22; AACATGCGTGAGA TTGTAAGT/ TCTGGATGTTGTTGGGAATCC (O'Donnell and Cigelnik (1997). The PCR was performed in a total volume of $50 \mu \mathrm{l}$ which consisted of $25 \mu 1$ MyTaq red mix (Bioline, UK), 2 $\mu 1$ of each primer, $4 \mu \mathrm{l}$ template DNA and $17 \mu \mathrm{lH}_{2} \mathrm{O}$ (RNase/DNase free). PCR amplification was performed in the Veriti-thermal cycler (Applied Biosystems, USA) starting with an initial denaturation step for ITS region at $95^{\circ} \mathrm{C}$ for $10 \mathrm{~min}$, followed by 35 cycles composed of denaturation at $95^{\circ} \mathrm{C}$ for $1 \mathrm{~min}$, annealing at $55^{\circ} \mathrm{C}$ for $1 \mathrm{~min}$, an extension step at $72^{\circ} \mathrm{C}$ for $1.5 \mathrm{~min}$, and a final extension step at $72^{\circ} \mathrm{C}$ for $10 \mathrm{~min}$. For TUB2, the conditions were as follows: one cycle of $3 \mathrm{~min}$ at $95^{\circ} \mathrm{C} ; 35$ cycles of $1 \mathrm{~min}$ at $94^{\circ} \mathrm{C}, 30 \mathrm{~s}$ at $60^{\circ} \mathrm{C}$ and 1 $\min$ at $72^{\circ} \mathrm{C}$, followed by one cycle of $10 \mathrm{~min}$ at $72^{\circ} \mathrm{C}$. The amplification products were analyzed by gel electrophoresis of $1.5 \%$ agarose in Trisacetate EDTA (TAE) buffer, stained with ethidium bromide $(50 \mu \mathrm{l} / \mathrm{L})$ and visualized on a UV transilluminator, (MultiDoc- It, UVP, UK). A 100bp DNA ladder was used to determine the size of the PCR products. Gel Extraction Kit (Qiagen, Germany) was used to purify PCR products from gel for subsequent sequencing. DNA sequencing was carried out in Macrogen Company (Seoul, South Korea). A BLAST search was performed through the NCBI website: http://blast.ncbi.nlm.nih.gov/ Blast.cgi. The alignment and molecular evolutionary analyses were assayed using the multiple sequence alignment program MEGA7(ver. 7.0.26) according to Kumar et al. (2016).

\section{Experimental infection:}

The artificial infection was carried out using the $F$. solani isolate (ESHA-1) following the method previously described by Abdallah et al. (2018). Microconidia were produced in PD broth incubated in a shaker incubator (Daihan, Korea) at $25^{\circ} \mathrm{C}$ with 
mild shaking (200 rpm) for 7 days. After being acclimated for laboratory conditions for 2 weeks, 90 apparently healthy crayfish (8-12 g body weight) of both sexes were equally divided into three groups (i.e. 30 individuals/group). The first group was injected intramuscularly with $0.1 \mathrm{ml}$ (containing $3 \times$ $10^{5}$ microconidia) in the third abdominal somite. Each crayfish of the second group received $0.1 \mathrm{ml}(3$ $\times 10^{6}$ microconidia) of a fungal suspension. The third group served as a mock control and injected with $0.1 \mathrm{ml}$ of sterile phosphate buffered saline (PBS). An additional non-infected group was used as an absolute control to monitor the experimental conditions and background mortality. Crayfish were kept for 14 days and both symptoms and mortalities were recorded. To fulfill Koch's postulate, the fungus was re-isolated from the inoculated crayfish gills and hemolymph.

\section{Antifungal activity of zinc oxidenanoparticles:}

The antifungal effect of zinc oxide nanoparticles ( $\mathrm{ZnO} N P s$; particle size $<100 \mathrm{~nm}, 50$ wt. $\%$ in $\mathrm{H}_{2} \mathrm{O}$, Sigma Aldrich, Switzerland) has been examined following the method of Pana'c ček et al. (2009). In brief, $F$. solani (ESHA-1) was grown on PDA at $25^{\circ} \mathrm{C}$ for 7 days, and then the microconidia numbers were adjusted to $7.5 \times 10^{6}$ microconidia/ml. Different concentrations of $\mathrm{ZnO}$ NPs were subject to sonication for $20 \mathrm{~min}$ at a velocity of 80 using a sonicator (Qsonica, USA). Melted Moller Hinton agar (MHA) was gently mixed with the sonicated $\mathrm{ZnO}$ NPs to give final concentrations of $15.50,7.75$, $3.88,1.94,0.97,0.48,0.24,0.12,0.06,0.03$, and 0 $\mathrm{mg} / \mathrm{ml}$. After agar solidification, $20 \mu \mathrm{l}$ of the $F$. solani microconidia suspension was spotted on the center of each of the plates containing the different concentrations of $\mathrm{ZnO}$ NPs as well as the control (0 $\mathrm{mg} / \mathrm{ml}$ ). The experiment was done in triplicates and the inoculated plates were incubated at $25^{\circ} \mathrm{C}$ and the fungal growth was monitored by measuring the radial growth daily up to 7 days.

\section{Statistical analysis:}

The results of mortalities induced by experimental infection as well as the effect of ZnO NPs on fungal growth were statistically analyzed using two-way ANOVA on the SPSS 10.0 (SPSS, Chicago, IL, USA) software program. Results represent the mean of triplicates \pm standard deviation (SD). The statistical significance was determined at a probability of $5 \%$ or less $(p<0.05)$.

\section{RESULTS}

\section{Fungal isolation and identification:}

Following isolation on the culture medium, microscopic examination of morphological characteristics helped in identification. When cultured on PDA, colonies appeared firstly cottony white then developed a characteristic rose violet color (Fig. 2). Microscopically, two types of Fusarium conidiospores were seen, one-celled microconidia, and multicellular banana-shaped macroconidia (Fig. 3). Microconidia were produced on lateral slightly branching microconidiophores which are up to $300 \mu \mathrm{m}$ in length. Based on the cultural characteristics and microscopic appearance of the growth, the isolated fungus was primarily identified as a member of the genus Fusarium, with subsequent molecular techniques being needed for accurate identification of the fungus on both genus and species levels.

\section{Molecular characterization of the isolates:}

The amplified ITS region of ESHA-1 (610 bp) and beta-tubulin gene (1375 bp) were visualized using ethidium bromide-stained agarose gels (Fig. 4). The amplified and sequenced fragments of the ITS region ( $600 \mathrm{bp})$ and the beta-tubulin gene $(\sim 1000$ bp) were deposited in the GenBank nucleotide sequence database under accession numbers of MK418794 and MK651040, respectively. A phylogenetic tree was constructed from multiple sequence alignment of ITS sequences (Fig. 5).

\section{Experimental Infection:}

Both fungal hyphae and conidia could be microscopically detected in gills of moribund and freshly dead crayfish 4 days post-infection. The mortalities in the first group started on the second day post-infection and reached the peak $(80 \%)$ at the day 13 of infection. Meanwhile, the second group exhibited mortalities that commenced from the first day of infection and recorded $100 \%$ cumulative mortalities on the seventh day post-infection. Both infected groups displayed black gills and the fungus was re-isolated from the gill lesions. The control group showed no mortalities or specific signs of the disease and no fungi were isolated from this group. There were significant differences $(P<0.05)$ when comparing the results of each group with the control (Fig. 6).

\section{Antifungal activity of zinc oxide nanoparticles (ZnO NPs):}

Addition of $\mathrm{ZnO}$ NPs to the culture medium of the fungus led to inhibition of the fungal radial growth and intensity. This inhibition appeared in the form of decrease of the colony size $(\mathrm{mm})$ in comparison with the fungus grown on plain medium (PDA with 0 $\mathrm{mg} / \mathrm{l} \mathrm{ZnO}$ NPs). The higher the concentration of nanoparticles in the medium, the greater the inhibition of the fungal growth (Fig. 7 and 8). A significant reduction $(p<0.05)$ in the fungal growth was recorded when comparing the results of each nanoparticle concentration with the control. The percent of reduction was as high as $35 \%$ following exposure to $\mathrm{ZnO}$ NPs of $15.5 \mathrm{mg} / \mathrm{ml} 7$ days postinoculation. 

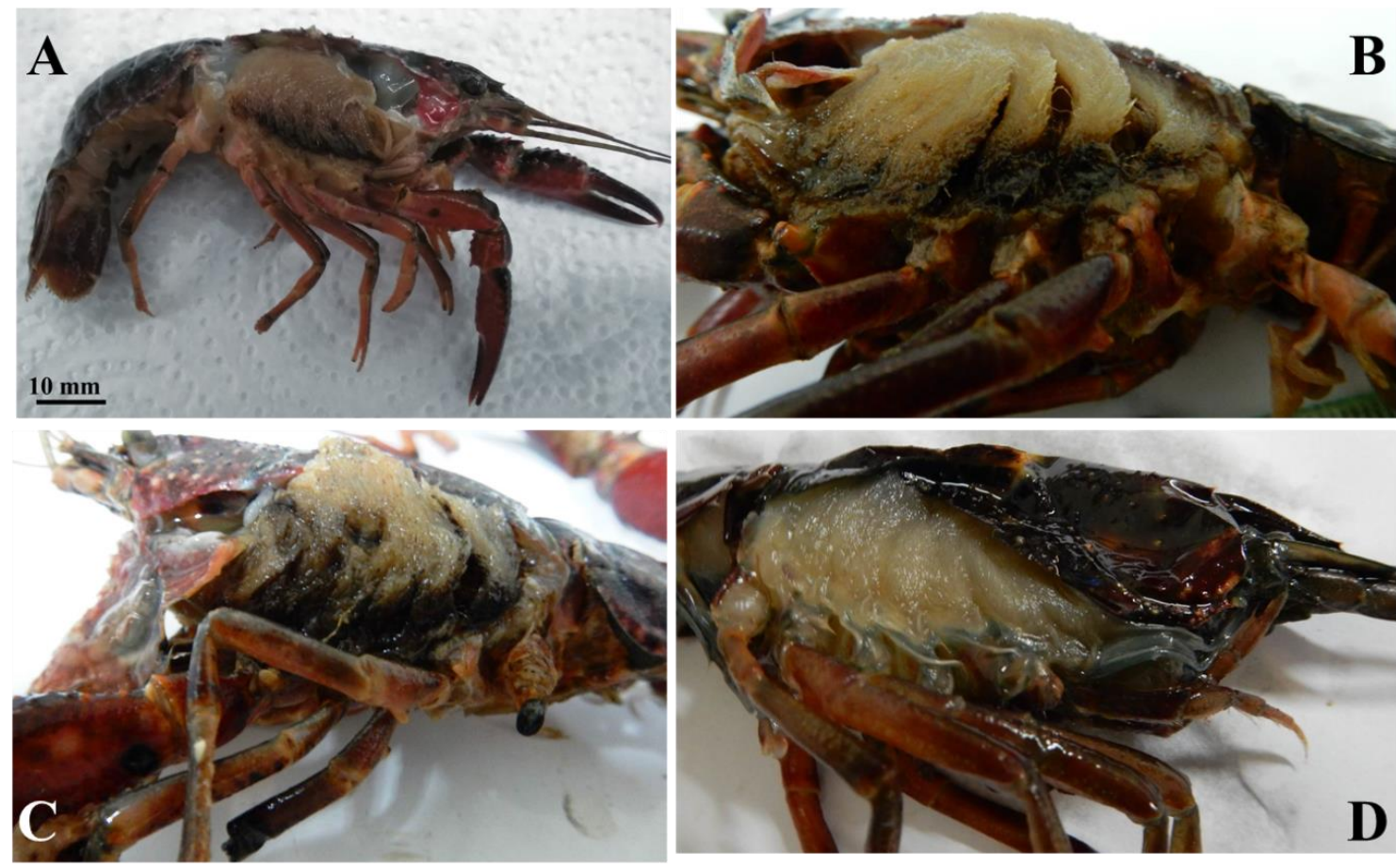

B

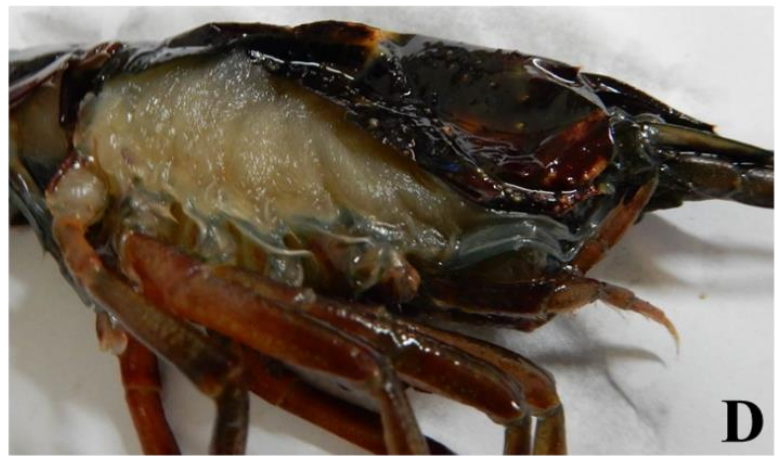

Fig. 1: Red swamp crayfish, Procambarus clarkii, naturally-infected with Fusarium solani showing different degrees of black gill lesions (melanisation; A-C) and healthy, non-infected, gills (D)

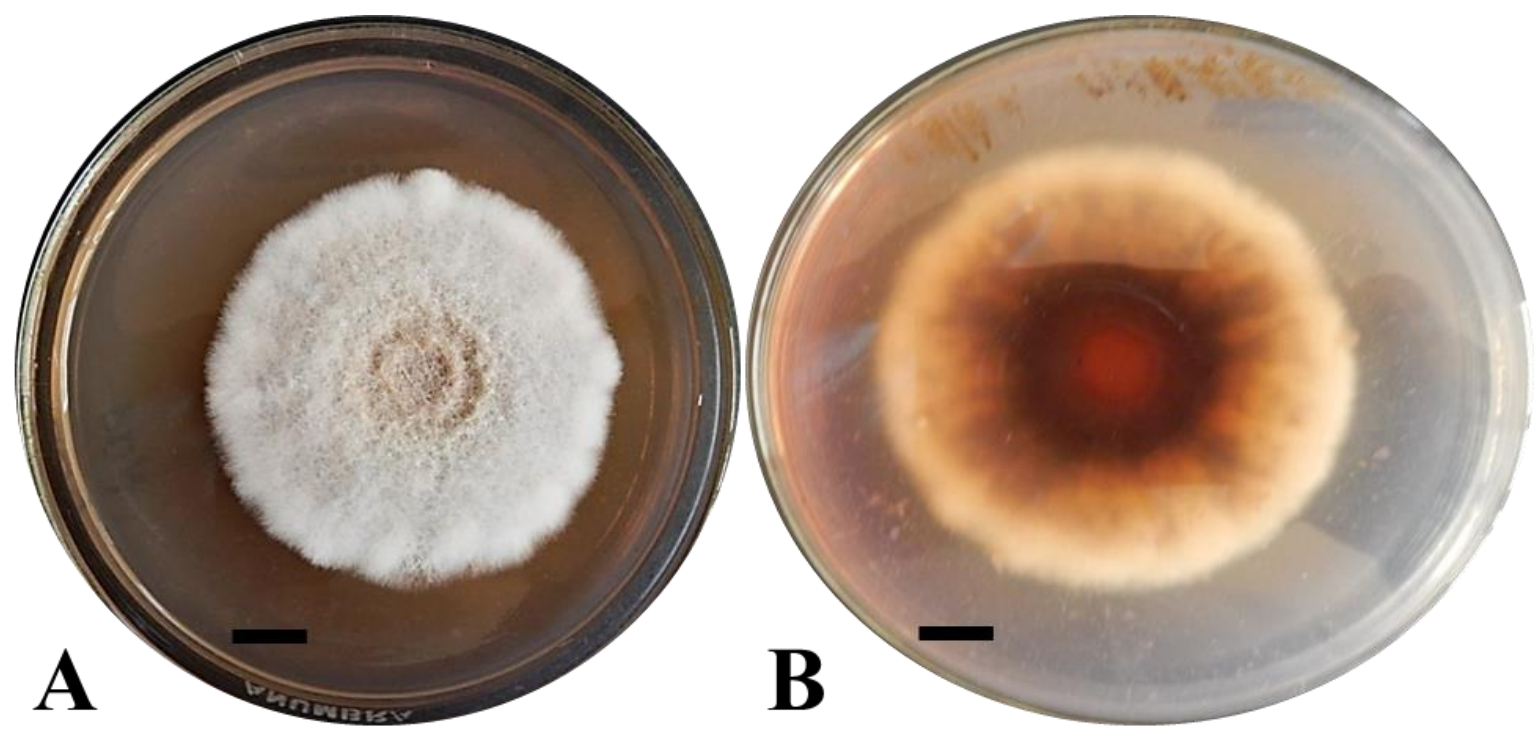

Fig. 2: Colony morphology of Fusarium solani isolated from red swamp crayfish, Procambarus clarkii and cultured on potato dextrose agar (PDA) 7 days post-inoculation. The colony appeared firstly cottony white (A) then developed a characteristic rose violet color (B). Scale bar: $10 \mathrm{~mm}$. 

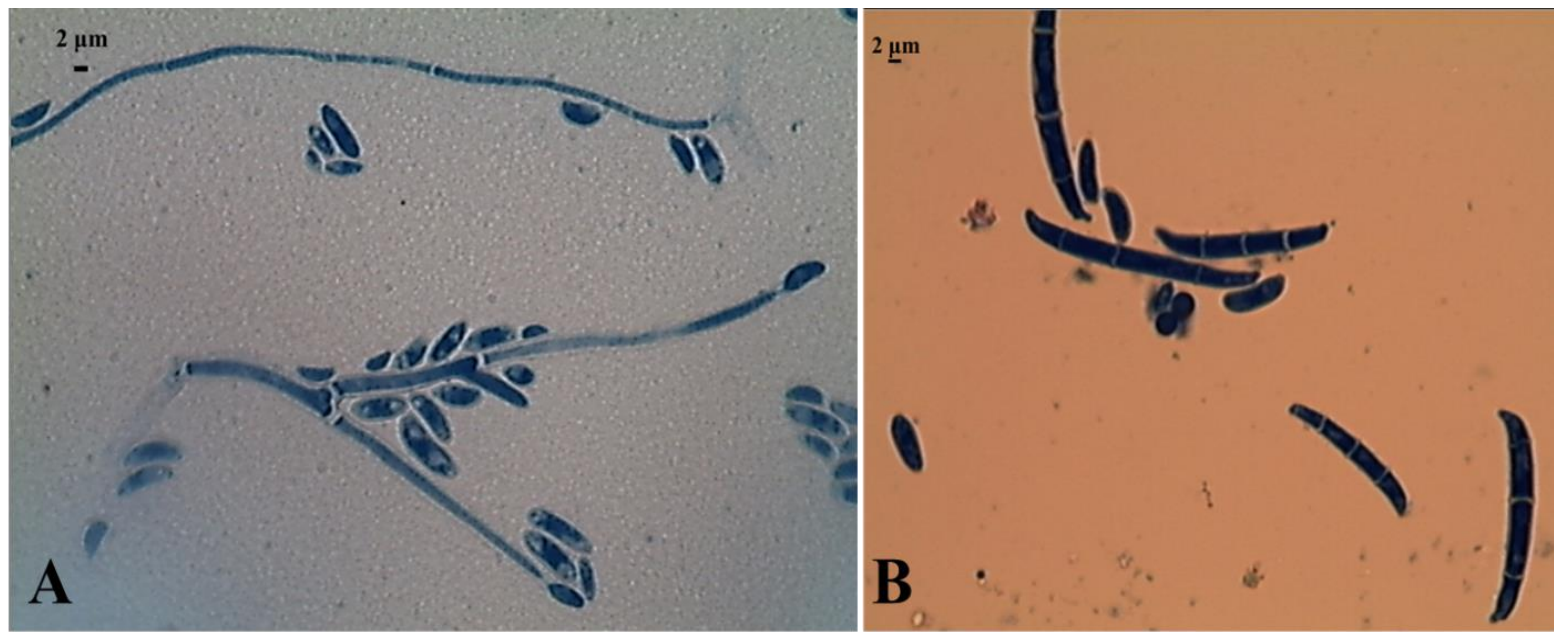

Fig. 3: Microscopic appearance of Fusarium solani isolated from red swamp crayfish, Procambarus clarkii showing long branched and unbranched aerial conidiophores, monophialidic, producing several microconidia (A) and three septate macroconidia (B).

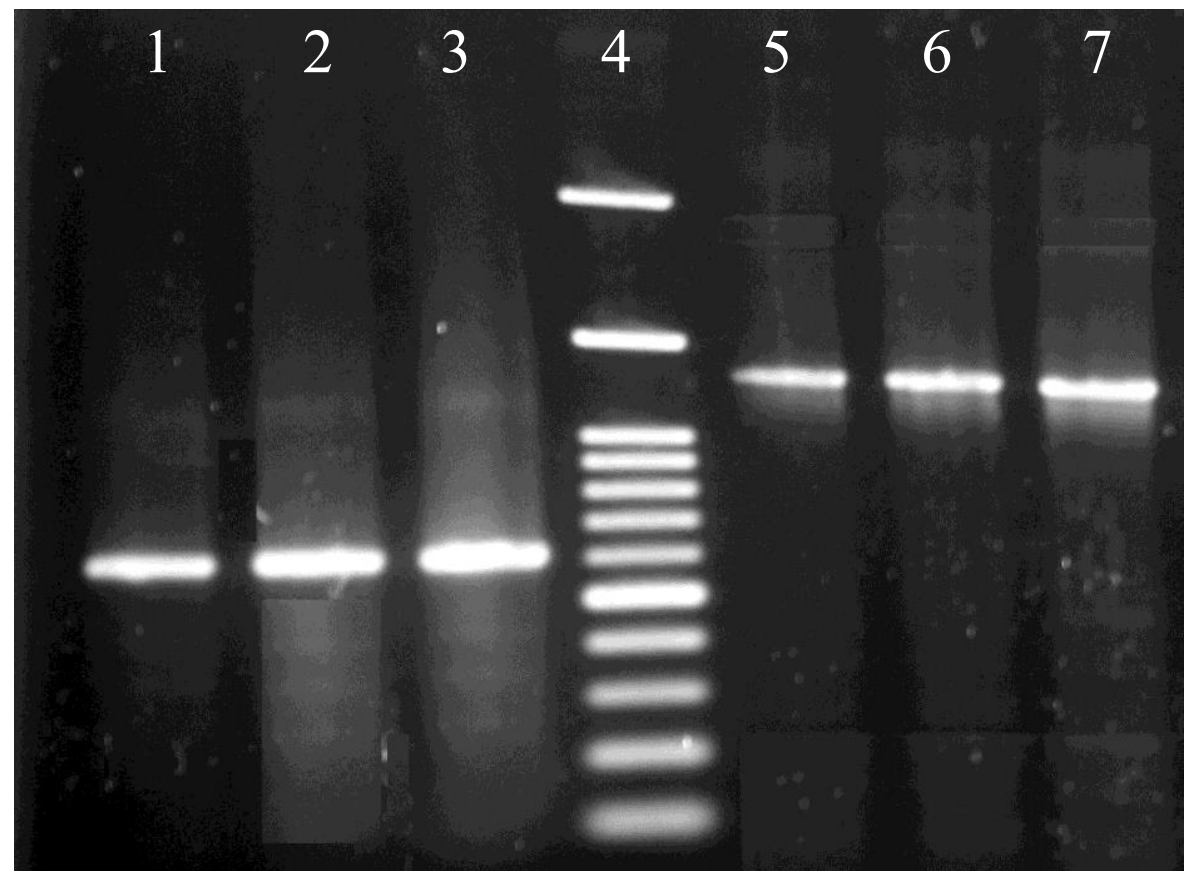

Fig. 4: Electrophoresed ethidium bromide-stained agarose gel of Fusarium solani isolates. Lanes 1-3: Amplified ITS regions (610 bp) of different isolates. Lane 4: 100 bp molecular marker. Lanes 5-7: Amplified betatubulin gene (TUB2; $1375 \mathrm{bp}$ ) of different isolates. 


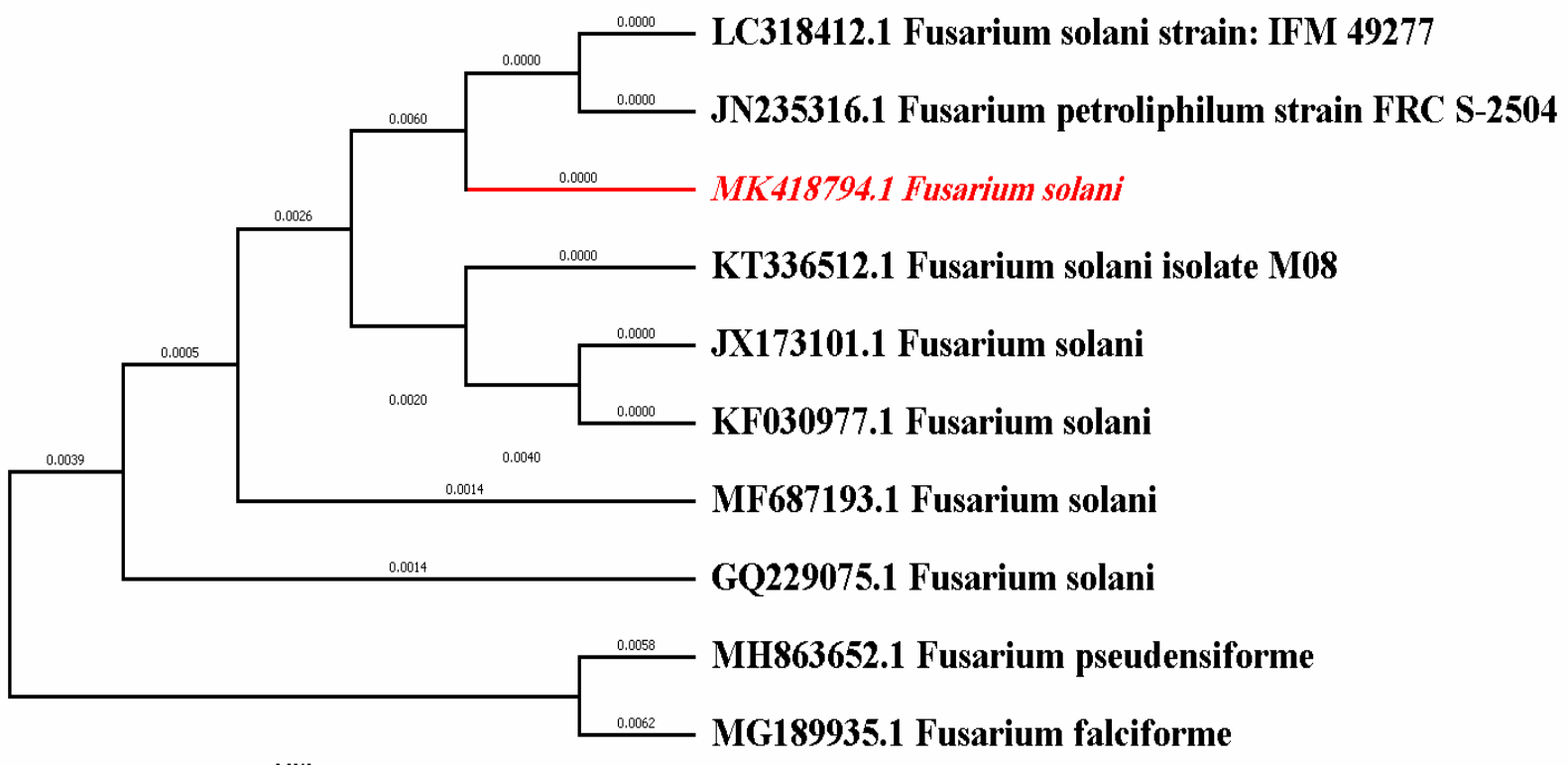

Fig. 5: A neighbor-joining tree based on ITS rDNA sequence of Fusarium solani (ESHA-1) isolated from red swamp crayfish, Procambarus clarkii with reference strains. Bars indicate genetic distance due to sequence variation.

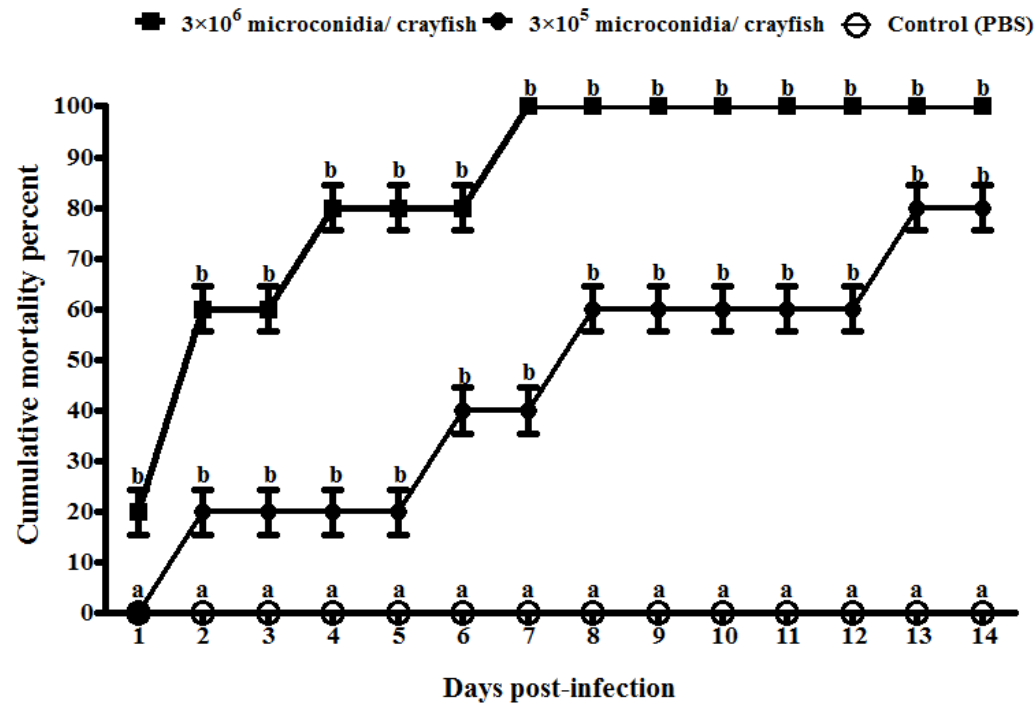

Fig. 6: Experimental infection of Fusarium solani (ESHA-1) in red swamp crayfish, Procambarus clarkii, by intramuscular injection of $0.1 \mathrm{ml}$ containing $3 \times 10^{6}, 3 \times 10^{5}$ microconidia or sterile PBS per individual. Different letters at each time point indicate a significant difference $(p<0.05)$. 

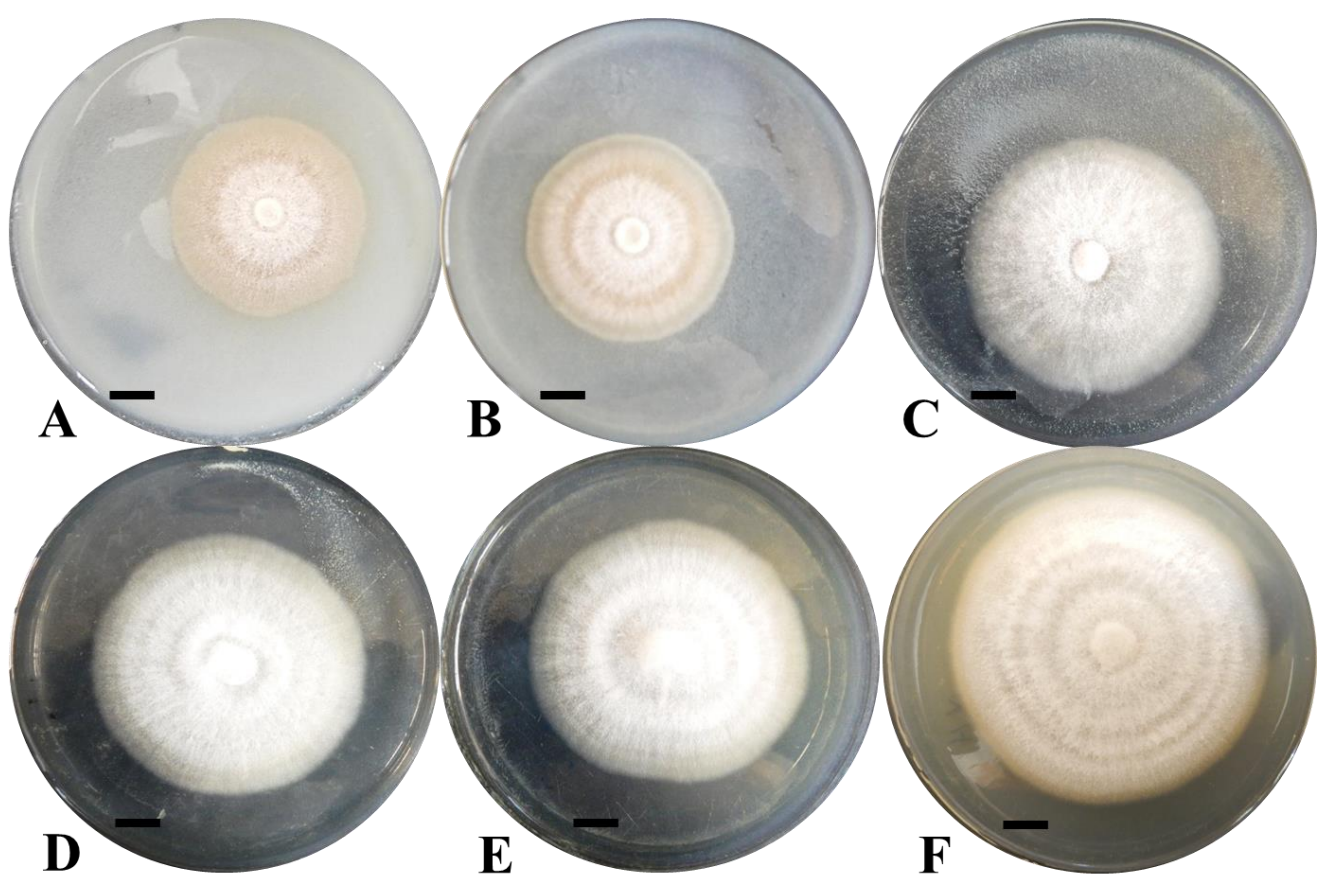

Fig. 7: Macroscopic mycelial growth of Fusarium solani on potato dextrose agar (PDA) supplemented with concentrations (mg/ml) of 15.50 (A), 7.75 (B), 1.94 (C), 0.24 (D), 0.12 (E) or 0 (F) of zinc oxide nanoparticles ( $\mathrm{ZnO}$ NPs) at 7 days after fungal inoculation. Significant inhibition of the fungal growth $(p$ $<0.05)$ was noticed when comparing growth at each concentration with the control $(0 \mathrm{mg} / \mathrm{mL})$. Scale bar: $10 \mathrm{~mm}$.

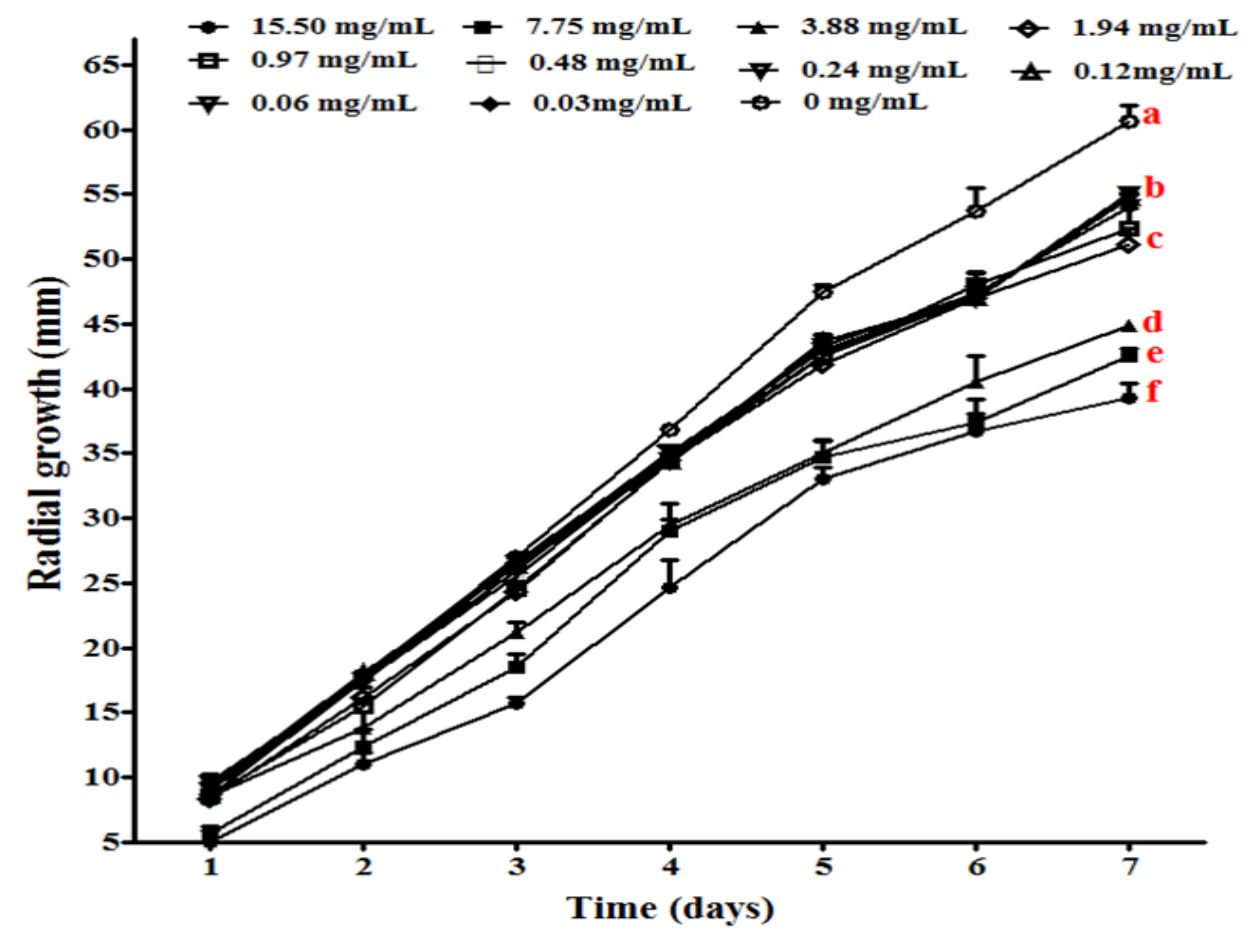

Fig. 8: Antifungal activities of zinc oxide nanoparticles ( $\mathrm{ZnO}$ NPs) against the tested strain of Fusarium solani (ESHA-1).The fungus was grown on media containing different concentrations of ZnO NPs. Colonies sizes (diameters) were measured at different time intervals (1-7 days) after inoculation. Different letters at the same time point indicate significant difference among tested groups $(p<0.05)$. 


\section{DISCUSSION}

Fungal infections of various species in the genus Fusarium have been reported to cause epidemics in diverse types of crustaceans including different species of crayfish and shrimp. These epidemics are responsible for economic losses both in wild and cultured conditions (Edsman et al., 2015; Hassan et al., 1999; Khoa et al., 2005; Makkonen et al., 2013; Velmurugan and Gopalakrishnan, 2014).

Though several fungi are known to attack the crayfish cuticle and gills (Makkonen et al., 2010) causing black (melanised) lesions, in the present study $F$. solani could be isolated in pure form from all investigated crayfish samples with obvious melanisation indicating its role in disease occurrence. The severe melanisation among crayfish stocks may cause difficulties or failures during molting, which sequentially can result in reduced production in wild stocks and probably population subsides in the most severe cases (Edsman et al., 2015).

The identification of Fusarium species is mainly based on unique characters of the shapes and sizes of macro- and microconidia, presence and absence of chlamydospores as well as colony morphology, pigmentations and growth rates on solid media (Leslie and Summerell, 2006). After being isolated on culture media (especially PDA), the morphological appearance of the fungal colonies with the specific rose violet color, helped as a first step in fungal identification. The same morphological characteristics have been previously reported by Chinain and Vey (1988) who isolated $F$. solani from the crustacean decapods, Astacus leptodactylus, and Pacifastacus leniusculus. Subsequently, the microscopic examination revealed the presence of long branched and unbranched aerial conidiophores that are monophialidic and produce several one-celled microconidia. Also, abundant banana-shaped macroconidia were observed with one to four septa. Similarly, Khoa et al. (2005) described the identical microscopic structure of $F$. solani isolated from black gills of $P$. japonicus.

Tough morphological characterization is a known method for identification; Hafizi et al. (2013) reported more than one morphotype of $F$. solani. Also, Shahnazi et al. (2012) classified F. solani isolates, based on colony morphology and pigmentation, into several groups. Thus molecular identification of the pathogen was needed. Amplification and sequencing of both ITS region and beta-tubulin gene confirmed the identification of the fungus as $F$. solani. Phylogenetic analysis revealed the identity of 98 to $100 \%$ between the $F$. solani isolates of the current study and the other Fusarium sequences obtained from GenBank.

To fulfill Koch`s postulates, experimental infection, using the isolate (ESHA-1), was carried out. The cumulative mortalities scaled up to $80 \%$ and $100 \%$ when crayfish were exposed to $3 \times 10^{5}$ and $3 \times 10^{6}$ microconidia/individual respectively. The fungus caused black gill lesions and could be successfully re-isolated from the infected crayfish. In their study, Khoa et al. (2005) recorded accumulative mortalities reaching $67 \%$ and $80 \%$ when 2 isolates of $F$. solani were intramuscularly injected into $P$. japonicus. Natural infection with $F$. solani can induce mortalities when the infection is triggered by some other factors including molting, fluctuations in temperature, or presence of wounds (Chinain and Vey, 1988).

In the current study, the use of $\mathrm{ZnO}$ NPs significantly reduced the fungal growth, even with the lowest concentration $(0.03 \mathrm{mg} / \mathrm{ml})$. The highest concentration used $(15.50 \mathrm{mg} / \mathrm{mL})$ induced a reduction in the colony diameter of $35 \%$ in comparison with the control $(0 \mathrm{mg} / \mathrm{mL})$ at the day 7 post-culture. A previous work (He et al., 2011) studied the antifungal activities of zinc oxide nanoparticles against two pathogenic fungi (Botrytis cinerea and Penicillium expansum) and showed significant inhibition of the growth of both fungi following treatment with the nanoparticles. $\mathrm{ZnO}$ NPs generated its activities by affecting cellular functions, causing deformity in the fungal hyphae, or preventing the development of conidiophores and conidia of the fungus, which eventually led to the death of fungal hyphae. Also, Sardellaa et al. (2018) reported that $\mathrm{ZnO}$ NPs possess significant antifungal activity against the pathogenic fungus, $P$. expansum. Furthermore, Arciniegas-Grijalba et al. (2017) investigated the antifungal activity of $\mathrm{ZnO} \mathrm{NPs}$ against the fungus, Erythricium salmonicolor. The authors measured the growth area at different time points as an indicator of the inhibitory effect on the growth of the fungus. They found that $\mathrm{ZnO} \mathrm{NPs}$ significantly inhibited the growth of E. salmonicolor. The high-resolution optical microscopy images showed deformation in the fungal growth pattern in the form of thinning of the fibers of the hyphae and a clumping tendency. The transmission electron microscopy images revealed liquefaction of the cytoplasmic content, the presence of a number of vacuoles and significant detachment of the cell wall.

\section{ACKNOWLEDGMENTS}

Thanks are due to Dr. Abdel-Rahim, I.R., Department of Botany and Microbiology, Faculty of Science, Assiut University for his valuable assistance in the morphological characterization of the isolated fungus.

\section{REFERENCES}

Abdallah, E.S.H.; Mahmoud, M.M. and AbdelRahim, I.R. (2018): Trichosporon jirovecii infection of red swamp crayfish 
(Procambarus clarkii). Journal of Fish Diseases 41: 1719-1732.

Alderman, D.J. and Polglase, J.L. (1985): Disinfection for crayfish plague. Aquacult Res 16: 203-205.

Arciniegas-Grijalba, P.A.; Patiñ-Portela, M.C.; Mosquera-Sa'nchez, L.P.; Guerrero-Vargas, J.A. and Rodri'guez-Pa'ez, J.E. (2017): ZnO nanoparticles (ZnO-NPs) and their antifungal activity against coffee fungus Erythricium salmonicolor. Appl. Nanosci 7: 225-241.

Baumgartner, W.A.; Hawke, J.P.; Bowles, K.; Varner, P.W. and Hasson, K.W. (2009): Primary diagnosis and surveillance of white spot syndrome virus in wild and farmed crawfish (Procambarus clarkii, $P$. zonangulus) in Louisiana, USA. Diseases of Aquatic Organisms 85: 15-22.

Chinain, M. and Vey, A. (1988): Experimental study of Fusarium solani: infections in Astacus leptodactylus and Pacifastacus leniusculus (Crustacea, Decapoda). Dis Aquat Org 5: 215-223.

Crow, G.L.; Brock, J.A. and Kaiser, S. (1995): Fusarium solani fungal infection of the lateral line canal system in captive scalloped hammerhead sharks, Sphyrna lewini, in Hawaii. J. Wildl. Dis. 31: 562-565.

Dörr, A.J.M.; Elia, A.C.; Rodolfi, M.; Garzoli, L.; Picco, A.M.; D'Amen, M. and Scalici, M. (2012): A model of co-occurrence: segregation and aggregation patterns in the mycoflora of the crayfish Procambarus clarkii in Lake Trasimeno (central Italy). J Limnol 71: 135-143.

Edgerton, B.F.; Evans, L.H.; Stephens, F.J. and Overstreet, R.M. (2002): Synopsis of freshwater crayfish diseases and commensal organisms. Aquaculture 206: 57-135.

Edsman, L.; Nyström, P.; Sandström, A.; Stenberg, M.; Kokko, H.; Tiitinen, V.; Makkonen, J. and Jussila, J. (2015): Eroded swimmeret syndrome in female crayfish Pacifastacus leniusculus associated with Aphanomyces astaci and Fusarium spp. infections. Diseases of Aquatic Organisms 112: 219-228.

Guarro, J., (2013): Fusariosis, a complex infection caused by a high diversity of fungal species refractory to treatment. Eur J Clin Microbiol Infect Dis 32: 1491-1500.

Hafizi, R.; Salleh, B. and Latiffah, Z. (2013): Morphological and molecular characterization of Fusarium. solani and F. oxysporum associated with crown disease of oil palm. Braz J Microbiol. 44: 959-968.

Hassan, S.; Vey, A.; Thuet, P. and Jean-Paul, T. (1999): Pathogenic and toxic effects of Fusarium oxysporum (Schlecht.) on survival and osmoregulatory capacity of Penaeus japonicus (Bate). Aquaculture 178: 209-224.
Hatai, K.; Kubota, S.S.; Kida, N. and Udagawa, S.-i. (1986): Fusarium oxysporum in Red Sea Bream (Pagrus sp.). Journal of Wildlife Diseases 22: 570-571.

He, L.; Liu, Y.; Mustapha, A. and Lin, M. (2011): Antifungal activity of zinc oxide nanoparticles against Botrytis cinerea and Penicillium expansum. Microbiol. Res 166: 207-215.

Holdich, D.M.; Reynolds, J.D.; Souty-Grosset, C. and Sibley, P.J. (2009): A review of the ever increasing threat to European crayfish from non-indigenous crayfish species. Knowledge and Management of Aquatic Ecosystems 11: $1-46$.

Hose, J.E.; Lightner, D.V.; Redman, R.M. and Danald, D.A. (1984): Observations on the pathogenesis of the imperfect fungus, Fusarium solani, in the California brown shrimp, Penaeus californiensis. J Invertebr Pathol 44: 292-303.

Jensen, A.B.; Aronstein, K.; Flores, J.M.; Vojvodic, S.; Palacio, M.A. and Spivak, M. (2013): Standard methods for fungal brood disease research. Journal of Apicultural Research 52: 1-20.

Johnson, P.T. (1983): Diseases caused by viruses, Rickettsiae, bacteria, and Fungi. In: Provenzano, A.J. (Ed.), The biology of Crustacea. VI. Pathobiology. Academic Press, New York, pp. 1-78.

Khoa, L.V.; Hatai, K. and Aoki, T. (2004): Fusarium incarnatum isolated from black tiger shrimp, Penaeus monodon Fabricius, with black gill disease cultured in Vietnam. Journal of Fish Diseases 27: 507-515.

Khoa, L.V.; Hatai, K.; Yuasa, A. and Sawada, K. (2005): Morphology and Molecular Phylogeny of Fusarium solani Isolated from Kuruma Prawn Penaeus japonicus with Black Gills. Fish Pathology 40: 103-109.

Kolattukudy, P.E. and Gamble, D.L. (1995): Nectria haemotococca: pathogenesis and host specificity in plant pathogenic fungi and nematodes. In: Kohmoto, K., Singh, U.S., Singh, R.P. (Eds.), Pathogenesis and host specificity in plant disease: histological, biochemical, genetic and molecular bases, Vol. II Eukaryotes: Pergamon, Elsevier Science Ltd., New York, pp. 83-102.

Kumar, S.; Stecher, G. and Tamura, K. (2016): MEGA7: Molecular Evolutionary Genetics Analysis version 7.0 for bigger datasets. Molecular Biology and Evolution 33: 18701874.

Leslie, J.F. and Summerell, B.A. (Eds.), (2006): The Fusarium laboratory manual.Blackwell Publishing Ltd, Oxford, London.

Makkonen, J.; Jussila, J.; Koistinen, L.; Paaver, T.; Hurt, M. and Kokko, H. (2013): Fusarium avenaceum causes burn spot disease 
syndrome in noble crayfish (Astacus astacus). J Invertebr Pathol 113: 184-190.

Makkonen, J.; Kokko, H.; Henttonen, P.; Kivistik, M.; Hurt, H.; Paaver, T. and Jussila, J. (2010): Fungal isolations from Saaremaa, Estonia: noble crayfish (Astacus astacus) with melanised spots. Freshwater Crayfish 17: $155-158$.

Nucci, M. and Anaissie, E. (2007): Fusarium Infections in Immunocompromised Patients. Clin. Microbiol. Rev. 20: 695-704.

O'Donnell, K. and Cigelnik, E. (1997): Two divergent dntragenomic rDNA ITS2 types within a monophyletic lineage of the fungus Fusarium are nonorthologous. Molecular Phylogenetics and Evolution 7: 103-116.

O'Donnell, K.; Humber, R.A.; Geiser, D.; Kang, S.; Park, B.; Robert, V.; Crous, P.W.; Johnston, P.R.; Aoki, T.; Rooney, A.P. and Rehner, S.A. (2012): Phylogenetic diversity of insectivorous fusaria inferred from multilocus DNA sequence data and their molecular identification via Fusarium-ID and Fusarium MLST. Mycologia 104: 427-445.

O'Donnell, K.; Sutton, D.A.; Fothergill, A.; McCarthy, D.; Rinaldi, M.G.; Brandt, M.E.; Zhang, N. and Geiser, D.M. (2008): Molecular phylogenetic diversity, multilocus haplotype nomenclature, and in vitro antifungal resistance within the Fusarium solani species complex. J. Clin. Microbiol. 46: 2477-2490.

Pana'c ček, A.; Kola'r', M.; Vec ěerova', R.; Prucek, R.; Soukupova', J.; Krys 'tof, V.r.; Hamal, P.; Zbor'il, R. and Kvi'tek, L. (2009): Antifungal activity of silver nanoparticles against Candida spp. Biomaterials 30: 6333-6340.

Quaglio, F.; Morolli, C.; Galuppi, R. and Bonoli, C. (2006): Preliminary investigation of diseasecausing organisms in the white-clawed crayfish Austropotamobius pallipes complex from streams of northern Italy. Bull Fr Peche Piscicult 380-381: 1271-1290.

Romanelli, A.M.; Sutton, D.A.; Thompson, E.H.; Rinaldi, M.G. and Wickes, B.L. (2010): Sequence-based identification of filamentous basidiomycetous fungi from clinical specimens: a cautionary note. Journal of Clinical Microbiology 48: 741-752.

Sardellaa, D.; Gatt, $R$. and Valdramidis, V.P. (2018): Assessing the efficacy of zinc oxide nanoparticles against Penicillium expansum by automated turbidimetric analysis. Mycology 9: 43-48.

Sarmiento-Ramirez, J.M.; Abella, E.M.; M.P.; Telleria, M.T.; Lopez-Jurado, L.F.; Marco, A. and Dieguez-Uribeondo, J. (2010): Fusarium solani is responsible for mass mortalities in nests of loggerhead sea turtle, Caretta caretta, in Boavista. Cape Verde. FEMS Microbiol. Lett. 312: 192-200.

Shahnazi, S.; Meon, S.; Vadamalai, G.; Ahmad, K. and Nejat, N. (2012): Morphological and molecular characterization of Fusarium spp. associated with yellowing disease of black pepper (Piper nigrum L.) in Malay. J Gen Plant Pathol. 78:: 160-169.

Soderhall, K. and Smith, V.J. (1986): Prophenoloxydase-Activating Cascade as a recognition and defence system in arthropods. In: Gupta, A.P. (Ed.), Hemocytic and humoralimmunity in arthropodsJohn Wiley \& Sons, pp. 251-286.

Velmurugan, K. and Gopalakrishnan, A. (2014): Culturable fungal diversity of brown-gill disease in three Penaeus species. International Journal of Research in Marine Sciences 3: 1-4.

White, T.J.; Bruns, T.D.; Lee, S.B. and Taylor, J.W. (1990): Amplification and direct sequencing of fungal ribosomal RNA genes for phylogenetics. In: Innis, M.A., Gelfand, D.H., Sninsky, J.J., White, T.J. (Eds.), PCR Protocols - a Guide to Methods and ApplicationsAcademic Press, San Diego, CA, pp. 315-322.

Yosra, M.I.E.S.; Mahmoud, M.M.; Ebtsam, S.H.; Sabah, I.M. and Elkamel, A.A. (2016): Subclinical vibriosis in red swamp crayfish, Procambarus clarkii. International Journal of Fisheries and Aquatic Studies 4: 119-123.

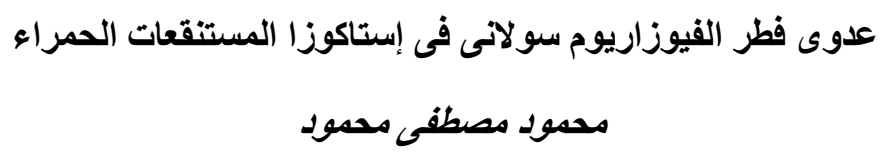

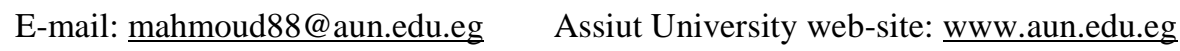

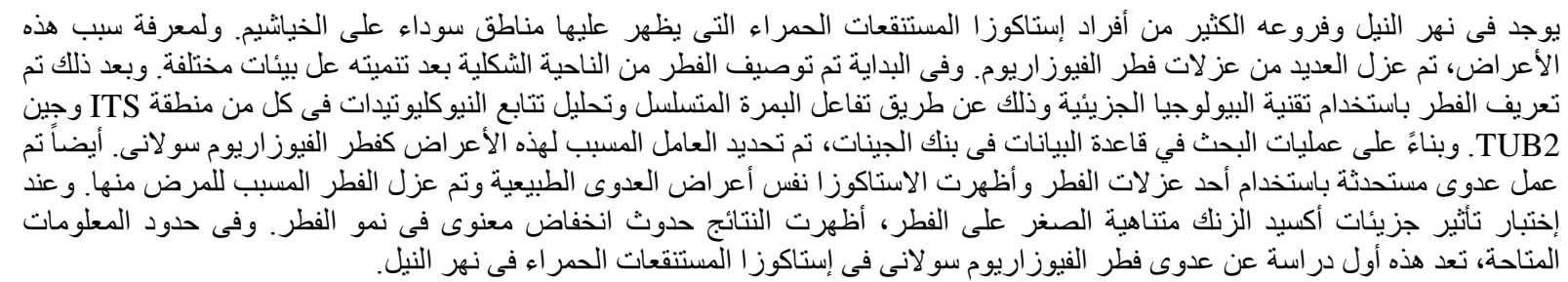

